\title{
Lomba Merpati: Place-making and Communal Signalling within Javanese Pigeon Racing
}

\author{
Leyla Stevens, University of Technology Sydney
}

Whenever I am in an unfamiliar city I become a walker. It is through aimless meandering that I can start to make sense of a new place, to physically understand its topography. In a place like Yogyakarta, where sidewalks are rarities and walking a fraught activity, public communal spaces - the south square, the local market, the closest soccer field — become my way of mapping and inhabiting the city.

This time in Yogyakarta I encounter the communal pull of pigeon training grounds. Once you learn to recognise the goalposts you can spot pigeon training grounds everywhere throughout the city. Four poles mark the corners of a square, rising around eight meters up into the air with a rope tied around the poles to form another square in the sky. Usually they are located on the periphery of rice fields, or within common grounds between several kampung (village/neighbourhood). Within the villages that line the main river artery of Yogyakarta, pigeon goalposts are set up on the narrow bridges that span the two sides of the river. These training grounds act as social gathering points for young men in the kampung. Peak training times occur in the coolness of late afternoon, before the last call to prayer. The grounds become a crowd of trainers, bystanders, pigeon cages stacked up on the ground and always at least one enterprising snack stand. 


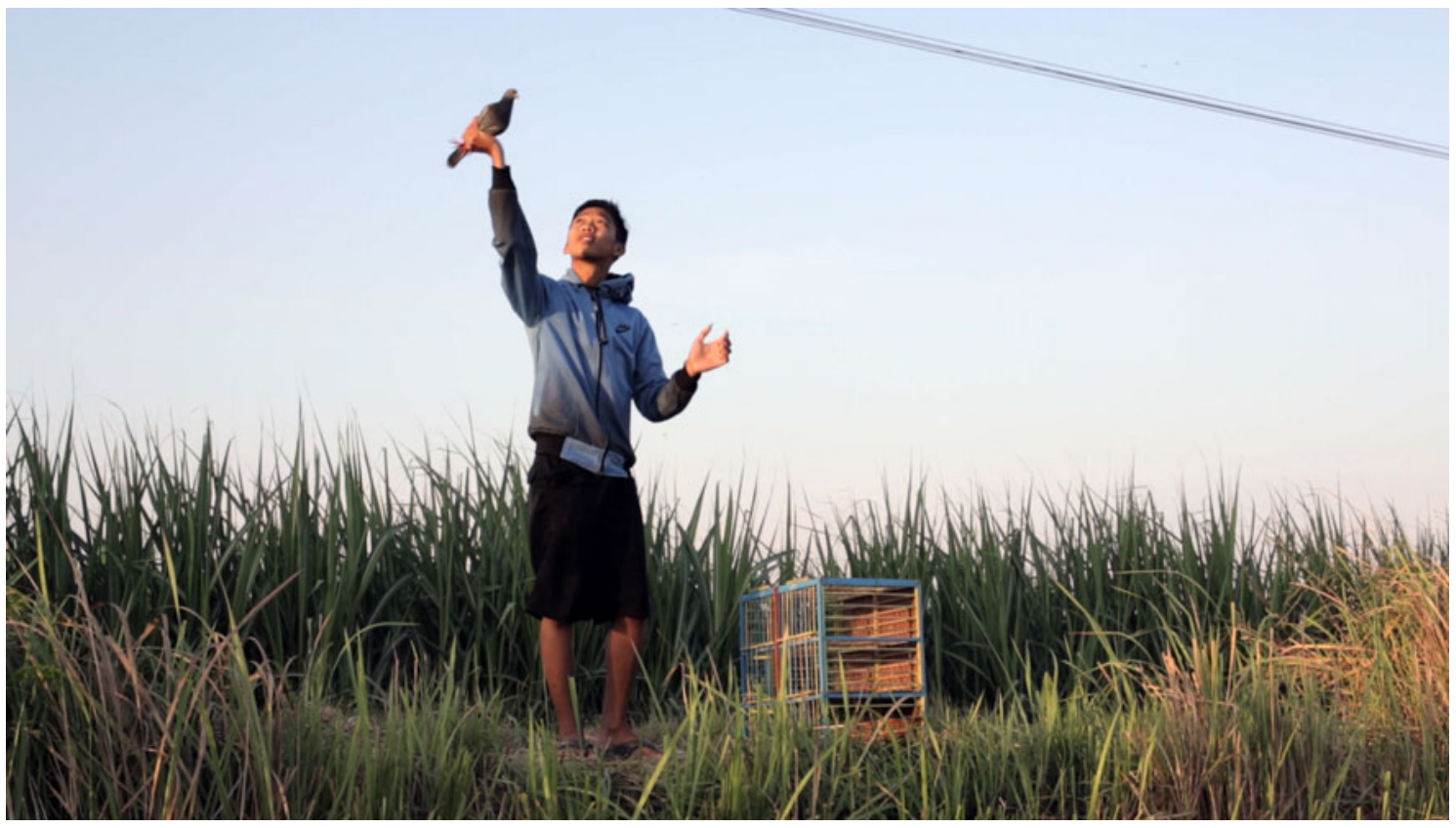

Figure 1: Pigeon Racing Training, Yogyakarta, digital photograph, 2015 C Leyla Stevens

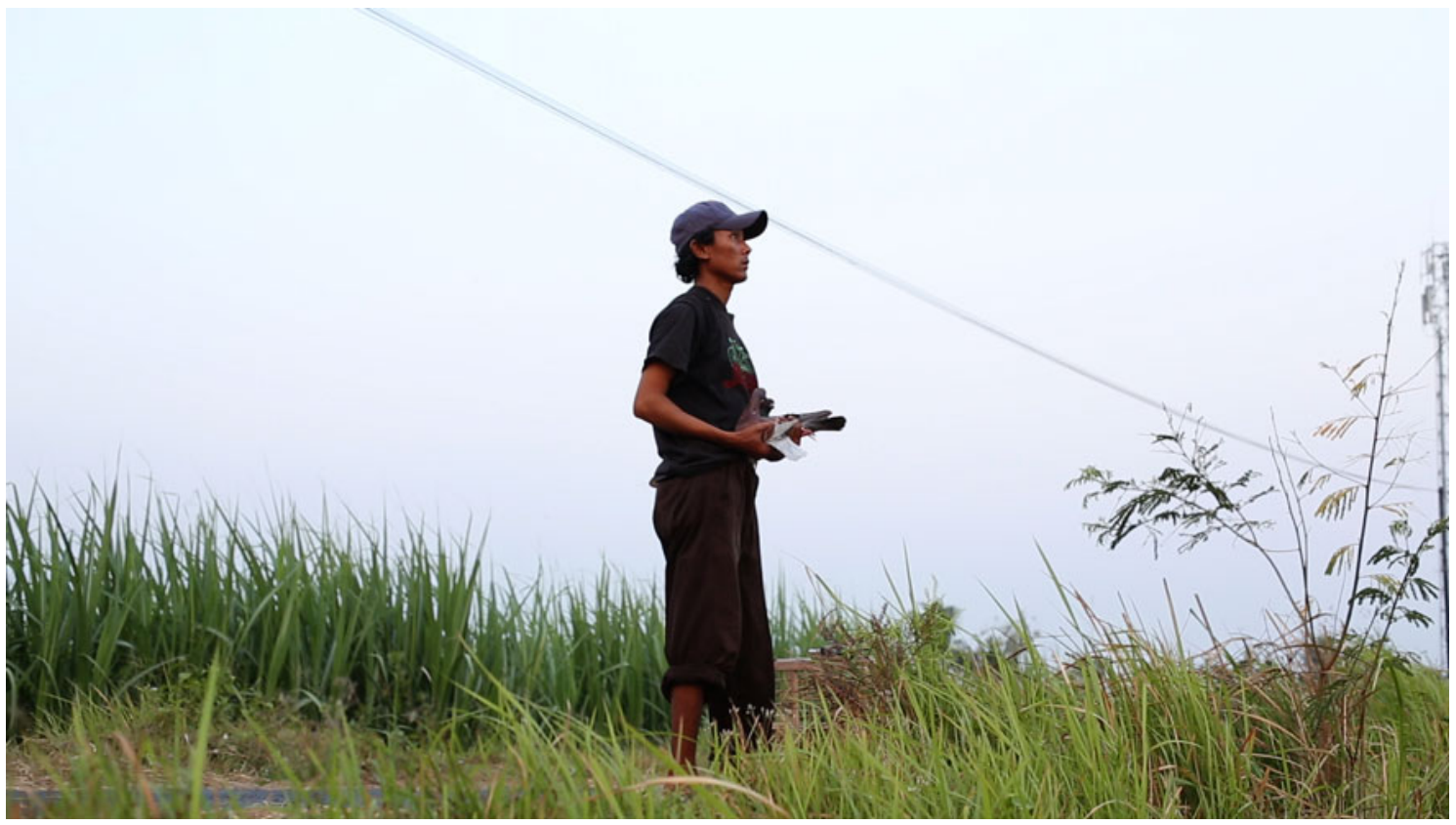

Figure 2: Pigeon Racing Training, Yogyakarta, digital photograph, 2015 C Leyla Stevens

Pigeons mate for life and pigeon racing in Java operates through separating the male bird from his hen, so he will instinctively fly back to her. The practice is known in European traditions as widowing. It is a sport that is enacted through a series of performative signalling between two locations. The men who release the male birds drive out to the starting point by motorbike with the pigeons in cages strapped to their 
backs. They release the male birds in pairs and then signal back to the men waiting at the goalposts by walkie talkies. The pigeon as it races from A to B is a homing device, the female essentially signalling to its mate. Back at the square men wait and watch for the pigeons to appear in the sky, much like how I know surfers to stand on the shore and watch for a set of waves to come in - a line of men linked through idle commentary, all watching the same point on the distant horizon. Once the male bird is in sight the pigeon handler will step into the square as if it was a stage. Holding the female bird in his hands, he will shake her up and down, at the same time calling loudly out to the male. Upon reaching the goalposts the male bird dives down through the top square and lands on the back of his mate. This type of racing is called merpati balap: short distance sprint racing.

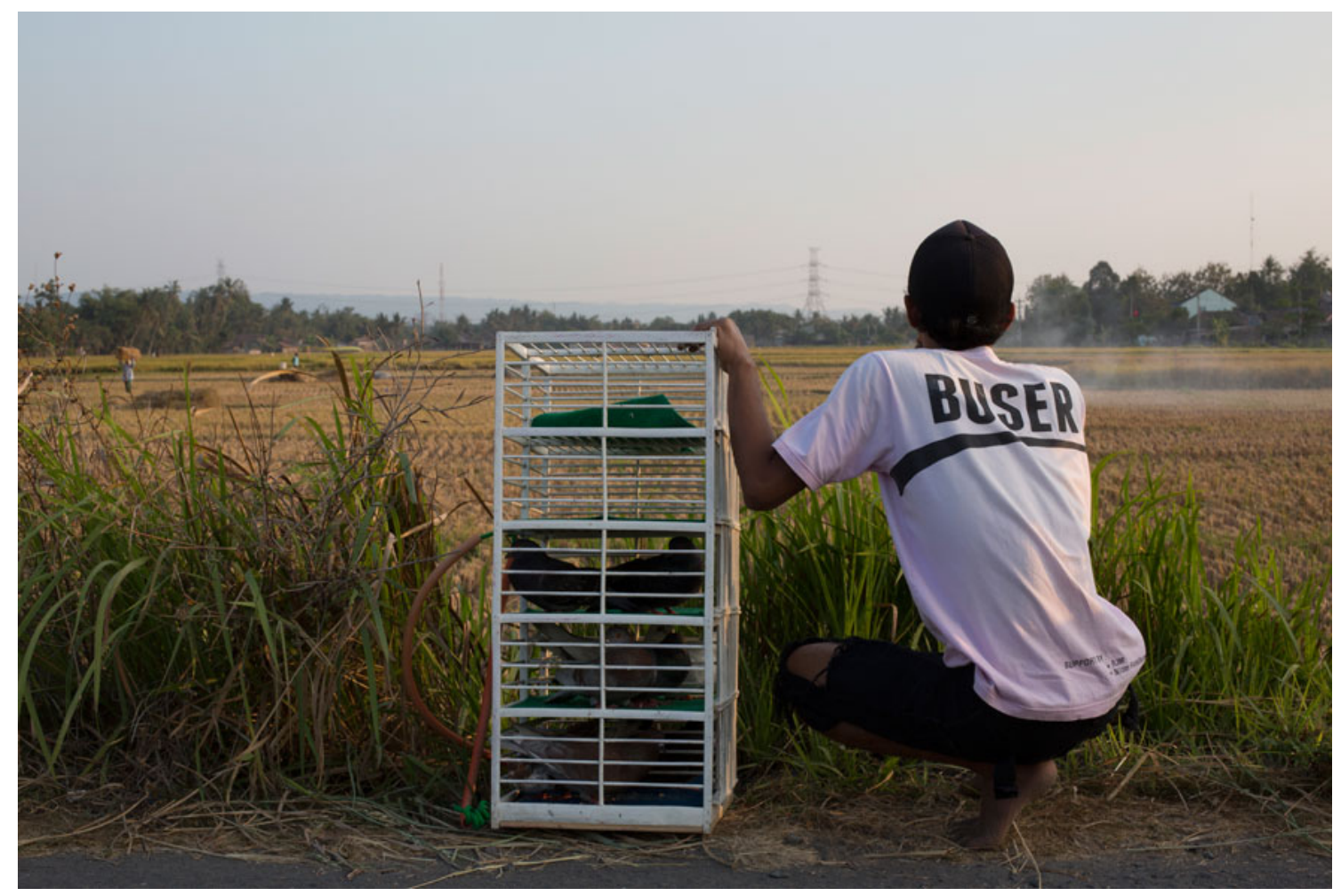

Figure 3: Pigeon Racing Training, Yogyakarta, digital photograph, 2015 C Leyla Stevens

For the men who partake in this sport, pigeon racing is a passion, a daily social practice, a currency and a source of pride. One handler, Mas Sigit, tells me it is all up to the personality of the pigeon that determines how fast they are. Some pigeons simply do not have what it takes. I ask him how many pigeons he owns. He tells me he owns three male birds, all newly trained. How much does a pigeon cost? It turns out it is not a small 
sum even for a young, unpaired male bird. He hopes to enter the next local competition in Bantul, where the winning prize is a motorbike. As we talk he releases one of his pigeons and it disappears into a rice field. The field is yet to be harvested and the stalks make it difficult to locate one small pigeon. Everyone forms a line that scours the field for the missing bird. Mas Sigit calls out with the female bird in one hand. Half an hour later it emerges, hopping, as one trainer laughs, like a frog between the stalks.

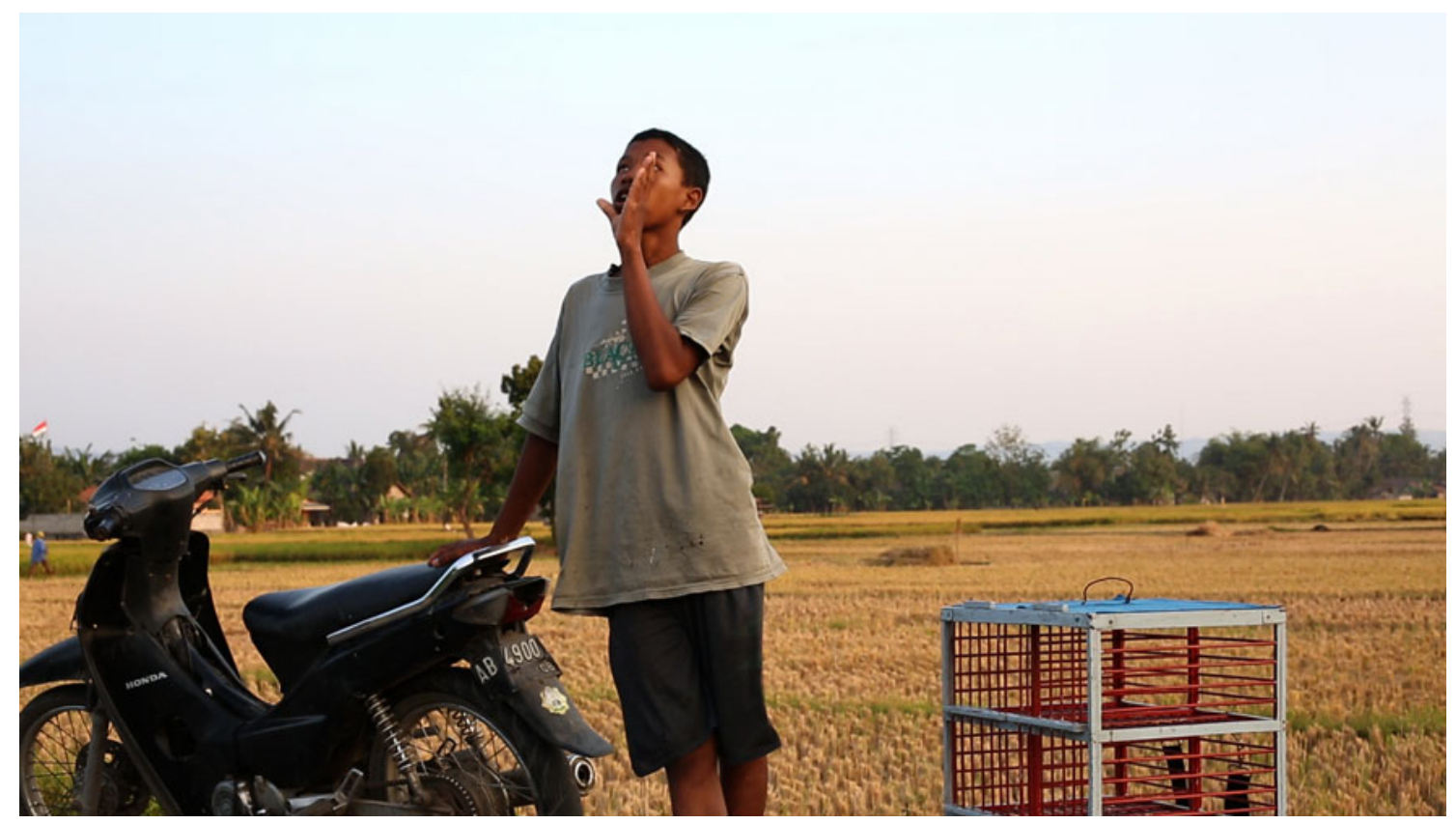

Figure 4: Pigeon Racing Training, Yogyakarta, digital photograph, 2015 C Leyla Stevens 